Journal of Advanced Research in Fluid Mechanics and Thermal Sciences

Journal homepage: www.akademiabaru.com/arfmts.html ISSN: 2289-7879

\title{
Air Temperature Measurement and Monitoring Inside Cold Plasma Treatment Reactor for Steel Wire Surface Cleaning Using Fiber Bragg Grating (FBG)
}

\author{
Mohd Fadthul Ikmal Misnal ${ }^{1}$, Norizah Redzuan ${ }^{1,}{ }^{*}$, Muhamad Nor Firdaus Zainal ${ }^{1}$, Norhayati \\ Ahmad $^{1}$, Raja Kamarulzaman Raja Ibrahim², Linda Agun ${ }^{1}$ \\ 1 Department of Materials, Manufacturing and Industrial Engineering, School of Mechanical Engineering, Faculty of Engineering, Universiti \\ Teknologi Malaysia, 81310 Skudai, Johor, Malaysia \\ 2 Department of Physics, Faculty of Science, Faculty of Engineering, Universiti Teknologi Malaysia, 81310 Skudai, Johor, Malaysia
}

\section{ARTICLE INFO ABSTRACT}

\section{Article history:}

Received 29 December 2019

Received in revised form 8 March 2020

Accepted 8 March 2020

Available online 24 April 2020

\section{Keywords:}

Air temperature; measurement; wire surface cleaning; fiber Bragg grating

\begin{abstract}
Surface cleaning is one of the critical preliminary process in wire manufacturing surface treatment for the purpose of improved surface wettability and adhesion. However, concern in terms of environmental impacts arises due to common practices of wetchemicals which led to severe human health. Surface cleaning using cold plasma treatment might become an alternative, but it seems that the issue of gas temperature measurement and monitoring have not been dealt with in depth, since the gas temperature can indicate the type of plasma formed inside the designed reactor. Fiber Bragg grating (FBG) might became an option for gas temperature measurement and monitoring. In this research, air temperature in cold plasma treatment reactor was measured and monitored using FBG, with effects of graphene electrode. Surface roughness of metal wire surface was measured and qualitative observation through optical microscope was carried out, before and after plasma treatment for the purpose of performance evaluation. From the results, it is found that type of plasma discharge formation has been successfully identified through air temperature profiling and monitoring using FBG. Highest surface roughness reduction is performed by filamentary type of discharge of $9 \mathrm{kV}$ applied voltage based on generated air temperature profile by FBG.
\end{abstract}

Copyright @ 2020 PENERBIT AKADEMIA BARU - All rights reserved

\section{Introduction}

Surface cleaning is regarded as critical preliminary process in almost every surface treatment especially surface coating for the sake of improved surface wettability and adhesion [1]. In wire manufacturing industry, wire surface cleaning is generating considerable concern in terms of environmental impacts due to excessive use of wet-chemicals such as oil and grease [2]. It is

\footnotetext{
* Corresponding author.

E-mail address: norizah@utm.my (Norizah Redzuan)
}

https://doi.org/10.37934/arfmts.70.1.155167 
becoming increasingly difficult to ignore the effects of common practice of wet-chemicals in wire surface cleaning industry, for example, the use of tri-chloroethane (1,1,1-TCE) cleaning solvent, which has been restricted by international agreement due to its harmful effects towards central nervous system, eventually led to confusion as well as dizziness [3]. The past two decades have witnessed a significant interest in wire surface cleaning using plasma treatment [2-6]. Initial work by Choi et al., [3] proved that plasma exposure on aluminium wire surface showed better surface cleaning compared to tri-chloroethane (1,1,1-TCE) cleaning solvent treatment. Other works by Korzec et al., [4], Kettler et al., [5] and Nakamura et al., [6] also reported the effectiveness of plasma treatment on metal wire surface cleaning with improvement in terms of surface wettability as well as surface morphology [4-6].

Technically, surface cleaning using plasma treatment can be categorized by physical plasma cleaning method and chemical plasma cleaning method. Physical plasma cleaning is described as the exposure of high energy ions bombardment of ionized carrier gases towards targeted surface. High power supply and low pressure are required to obtain maximum energy level of ions before it hits metal wire surface. On the other hand, chemical plasma cleaning involved the active species generation such as electrons, radicals, ions as well as byproducts, eventually followed by diffusion on targeted surface through baffle assembly [7]. Interest of plasma treatment for wire surface cleaning application has been well-recognized due to its high potential in terms of environmental sustainability. However, despite this interest, it seems that the issue of gas temperature measurement and monitoring have not been dealt with in depth. Temperature is among most important measurement in physical process because it affects the atomic or molecular kinetic energy in plasma cleaning process [8]. Thus, the main focus towards air temperature measurement and monitoring is to ensure that plasma surface cleaning is carried out in low temperature environment using electrical energy rather than heat energy. In fact, surface cleaning by thermal plasma (hot plasma) heating with temperature of $600{ }^{\circ} \mathrm{C}$ and above led to undesirable exothermic formation of metal carbides as well as the polymerization of organic contaminants [1].

Conventionally, gas temperature measurement and monitoring has been carried out by using thermocouple [9-11]. However, few researchers have addressed the issue of technical errors such as radiative exchange between the probe junction with the surrounding, thermal inertia, heat conduction along the wires as well as catalytic effects [12-13]. Alternatively, for the past five years, Fiber Bragg grating (FBG) might became an option for gas temperature sensor [14-15]. Ability of FBG to being located and embedded inside the plasma reactor might provide accurate gas temperature measurement and monitoring for the sake of deep understanding on physical process in plasma cleaning process [15]. Another interesting part in this study is the involvement of graphene as an electrode. In addition, the thermal behavior of graphene has not been dealt with in depth as most of the researchers assumed that graphene electrode exhibited same thermal properties with graphite [16-17]. Despite its uncertainty in terms of thermal behavior, graphene is set to become an important component in electrical and optical devices especially as electrodes due to its mechanical strength, transparency, high charge mobility and flexibility [18-21].

Several performance evaluation techniques such as surface roughness profile [22-23] and scanning electron microscopy (SEM) analysis $[2-3,6]$ can be carried out in order to determine the influence of gas temperature measurement and monitoring on plasma treatment towards the metal wire surface cleaning effectiveness. Surface roughness profile was determined by detecting the uneven metal surface with peaks of various heights. Reduction of surface roughness indicated the ability of plasma treatment to clean and remove the contaminants (such as oxides growing on metal wire surface as well as surface exposure to ambient atmosphere) from metal wire surface [1]. Qualitatively, the removal of contaminants should lead to improved morphology of metal wire in 
terms of producing shinier surface, as a result of oxide removal [24]. Based on the current situation, air temperature measurement and monitoring are required in cold plasma treatment for metal wire surface cleaning for the sake of deep understanding of physical process in plasma cleaning process. Therefore, in this study, air temperature in cold plasma treatment reactor was measured and monitored using FBG, with effects of graphene electrode. Surface roughness of metal wire surface was measured and qualitative observation through optical microscope was carried out, before and after plasma treatment for the purpose of performance evaluation.

\section{Methodology}

\subsection{Plasma Reactor Design}

Development and designing of plasma reactor system prototype as well as instrumentation set up is required before gas temperature could be measured and eventually monitored. Figure 1 shows the schematic and actual design of plasma reactor system. With the presence of high voltage power supply, electrodes (anode and cathode), dielectric materials and working gas, this system can function properly. In this study, graphene sheet was used as anode electrode while untreated steel wire was used as cathode electrode. Air was used as the carrier gas for plasma to generate, whereas glass tube acts as dielectric barrier in our plasma reactor.

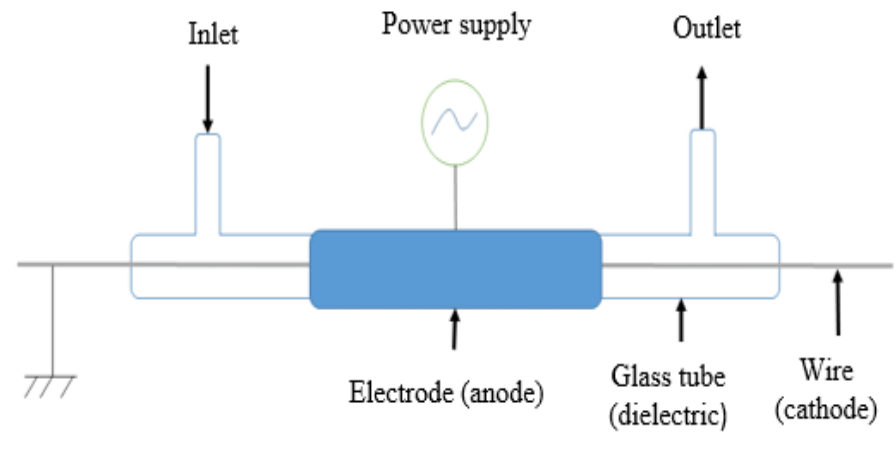

Fig. 1. Schematic (left hand side) and actual (right hand side) design of plasma discharge system

Figure 2 illustrates the air temperature and monitoring setup. The plasma reactor was fabricated using a $150 \mathrm{~mm}$ borosilicate glass tube with inner and outer diameters of $5 \mathrm{~mm}$ and $6 \mathrm{~mm}$, respectively. Air compressor (FD 1006 A, 1 HP) was used to supply air through the plasma reactor. The air flowrate was controlled using flow meter (MKS Multi Gas Controller 647C) and was kept constant at flowrate and pressure of $5 \mathrm{sccm}$ and 0.15 mbar respectively. In this experiment, power supply (PVM500 Plasma Resonant and Dielectric Barrier Corona Driver) becomes the primary high voltage source, thus enabled the electrical discharge between two electrodes, graphene sheet (anode) and untreated steel wire (cathode). With ability to supply voltage from $0.5 \mathrm{kV}$ to $40 \mathrm{kV}$ and frequency ranged between $20 \mathrm{kHz}$ to $70 \mathrm{kHz}$, the corresponding power supply is selected in order to supply three different applied voltages which are $7 \mathrm{kV}, 8 \mathrm{kV}$ and $9 \mathrm{kV}$ with maximum frequency of 70 $\mathrm{kHz}$. The fiber Bragg grating (FBG) was placed on top of untreated steel wire surface, so that air temperature can be detected through fiber optic interrogator, as gas temperature data were displayed on PC monitor. Detailed operational parameters of plasma reactor are summarized in Table 1 while description of FBG is further discussed in section 2.2. 


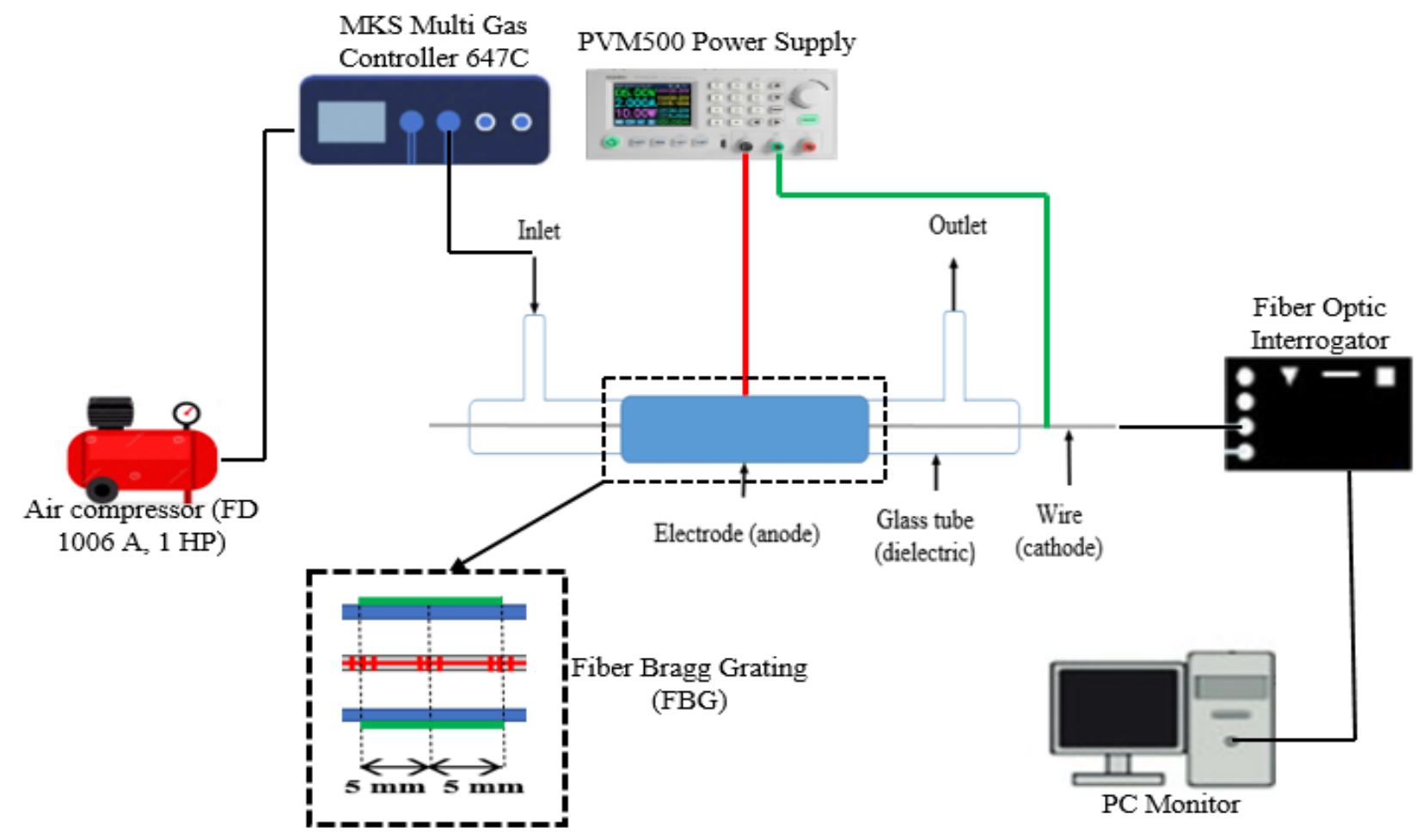

Fig. 2. Air temperature measurement and monitoring setup

Table 1

Operational parameters of plasma discharge model

\begin{tabular}{ll}
\hline Set Up/Materials & Operational Parameters \\
\hline Tested applied voltages & Applied voltages: $7 \mathrm{kV}, 8 \mathrm{kV}, 9 \mathrm{kV}$ \\
& Frequency: $70 \mathrm{kHz}$ \\
Plasma treatment duration & $5 \mathrm{sec}, 10 \mathrm{sec}, 15 \mathrm{sec}, 20 \mathrm{sec}, 25 \mathrm{sec}, 30 \mathrm{sec}$ \\
Graphene sheet (anode electrode) & Length: $10 \mathrm{~mm}$ \\
& Thickness: $0.025 \mathrm{~mm}$ \\
Glass tube (dielectric) & Length: $150 \mathrm{~mm}$ \\
& Inner diameter: $5 \mathrm{~mm}$ \\
& Outer diameter: $6 \mathrm{~mm}$ \\
& Thickness: $1 \mathrm{~mm}$ \\
Air (carrier gas) & Air flowrate: $5 \mathrm{sccm}$ \\
& Air pressure: $0.15 \mathrm{mbar}$ \\
Untreated steel wire (treated & Length: $150 \mathrm{~mm}$ \\
specimen/cathode electrode) &
\end{tabular}

\subsection{Air Temperature Measurement and Monitoring}

Fiber Bragg grating (FBG) formation is a result of intense ultraviolet (UV) light source introduced into single-mode fiber core in order to create periodic perturbation, eventually leads to permanent increment of fiber core refractive index and produces a fixed modulation index known as Bragg grating. Light source corresponded to Bragg grating will be reflected at certain wavelength, as others will be transmitted, according to Fresnel reflection. The reflected light is given by the equation [2526]:

$\lambda_{B}=2 n_{\text {eff }} \Lambda$ 
where $n_{\text {eff }}$ is fiber effective refractive index while $\Lambda$ is period of Bragg grating. There will be a sinificant change in both of $\lambda_{B}$ and $n_{e f f}$ when gas temperature is detected on fiber core. Shifting of Bragg wavelength and change in refractive index happened when there is thermal as well as heat expansion caused by applied temperature. Operationally, temperature sensing for FBG can be formulated as [26]:

$\frac{\Delta \lambda_{B}}{\lambda_{B}}=(\alpha+\xi) \Delta T$

where $\alpha$ and $\xi$ represent thermal expansion and thermo-optic coefficient.

In our air temperature measurement and monitoring, the FBG is embedded in plasma reactor, on top of untreated steel wire and located in the middle of reactor as illustrated in Figure 3 . The FBG inscribed is a uniform grating single mode fiber with operating grating length, bandwith, wavelength and reflectivity of $5 \mathrm{~cm}, 0.5 \mathrm{~nm}, 1550 \mathrm{~nm}$ and $90 \%$, respectively. Meanwhile, FBG temperature sensitivity calculated at $10.8 \mathrm{pm} /{ }^{\circ} \mathrm{C}$, obtained from calibration curve.

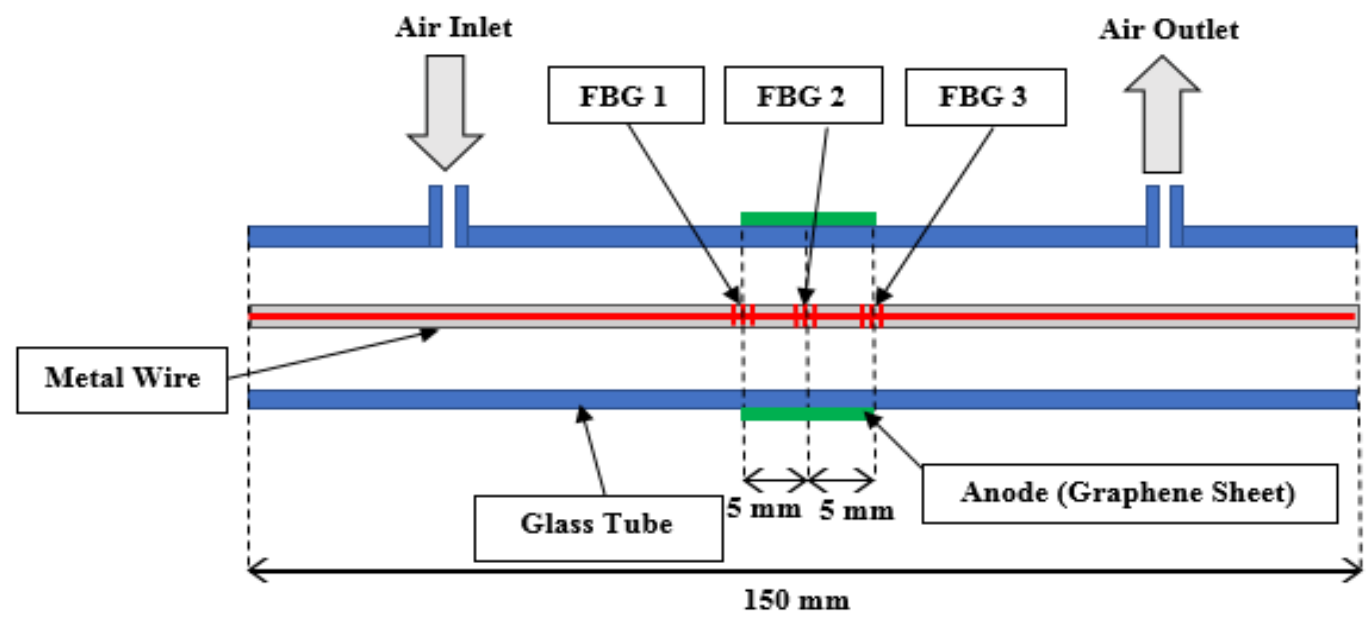

Fig. 3. Illustration of Fiber Bragg grating (FBG) setup inside plasma reactor

\subsection{Performance Evaluation}

The performance of plasma treatment was evaluated using the percentage of surface roughness reduction by comparing the surface roughness of untreated steel wire with treated steel wire. The surface roughness analysis is carried out in the middle spot within plasma discharge region using Mitutoyo SJ-310 portable surface roughness test machine. For surface roughness measurement, arithmetical mean surface roughness value profile, $R_{A}$ is considered. In our case, percentage of surface roughness reduction is defined by:

$R_{A}=\left|\frac{\left(R_{A}\right)_{\text {treated }}-\left(R_{A}\right)_{\text {untreated }}}{\left(R_{A}\right)_{\text {untreated }}}\right| \times 100 \%$

where $\left(R_{A}\right)_{\text {treated }}$ is the surface roughness of plasma treated steel wire and $\left(R_{A}\right)_{\text {untreated }}$ is the surface roughness of untreated steel wire. Only selected treatment time ranges of $5 \mathrm{sec}, 10 \mathrm{sec}, 15$ $\mathrm{sec}, 20 \mathrm{sec}, 25 \mathrm{sec}$ and $30 \mathrm{sec}$ were selected for performance evaluation for all mentioned applied voltages. For qualitative analysis, the surface morphology of every treated and untreated steel wire samples was observed and eventually compared by using optical microscope. 


\section{Results}

\subsection{Air Temperature Measurement and Monitoring}

Air temperature measurement and monitoring profiles were illustrated in Figure 4, Figure 5 and Figure $67 \mathrm{kV}, 8 \mathrm{kV}$ as well as $9 \mathrm{kV}$ applied voltage correspondingly. The graph in Figure 4 for $7 \mathrm{kV}$ shows that there has been a gradual increase in air temperature measurement from 20 to $25^{\circ} \mathrm{C}$ within $30 \mathrm{sec}$ treatment time. Meanwhile, the graph in Figure 5 for $8 \mathrm{kV}$ shows that there has been a gradual increase in air temperature measurement from 20 to $29^{\circ} \mathrm{C}$ within $30 \mathrm{sec}$ treatment time. For both corresponding $7 \mathrm{kV}$ and $8 \mathrm{kV}$ applied voltages, highest air temperature profiles were recorded by FBG 2, followed by FBG 1 and FBG 3.

Linear air temperature increment was presented in both $7 \mathrm{kV}$ and $8 \mathrm{kV}$ applied voltages. Linear temperature rises in all plasma temperature profiles reflected to Townsend discharge, which initiated by the impact ionization acceleration due to surface charge accumulation from high voltage induction [15]. Interestingly, the air temperature trends recorded by FBG 1, FBG 2 and FBG 3 for $7 \mathrm{kV}$ and $8 \mathrm{kV}$ has shown almost similar profiles with only slight difference in air temperature measurement and monitoring. We believe that this is the proof of existence of homogenous or uniform cold plasma discharge. During the discharge development, the homogeneity is mainly controlled by the electrical current or voltage imposed as well as the air ability to be slowly ionized. Lower voltage during the discharge development is the main contributor to enhance homogenous cold plasma discharge [2728].

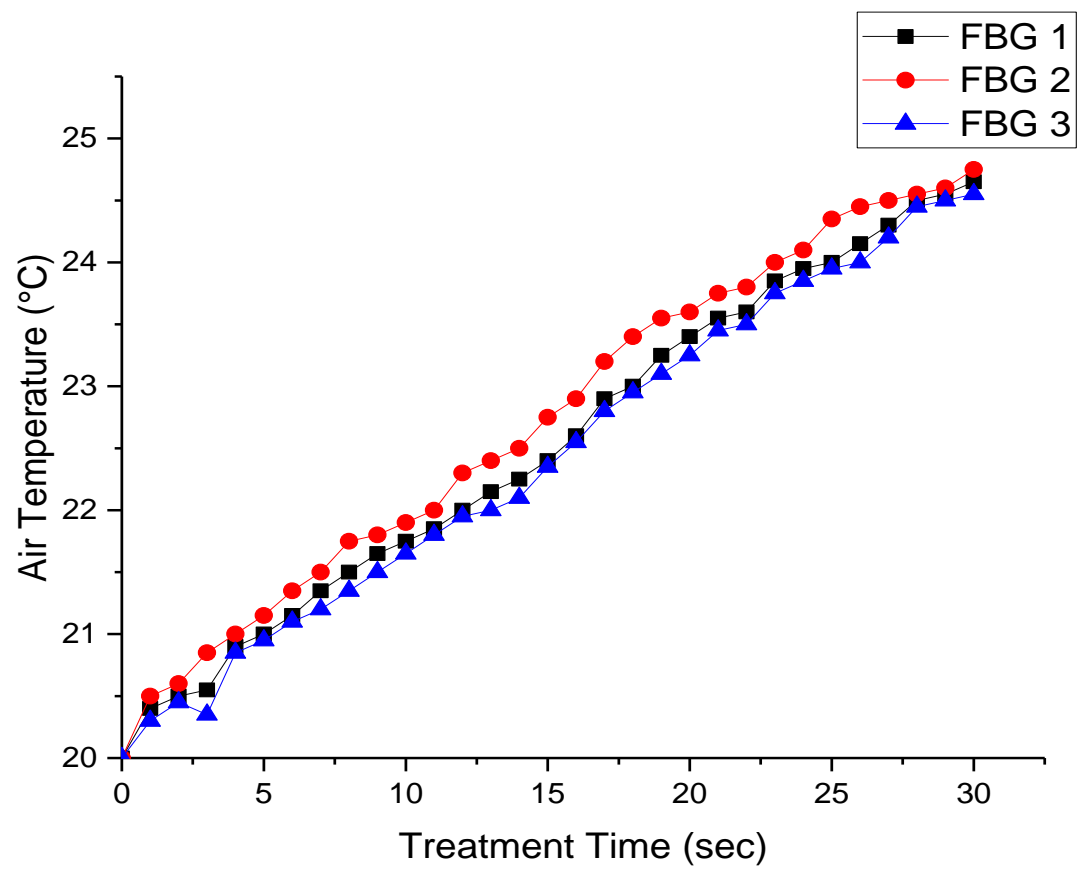

Fig. 4. Air temperature profile for $7 \mathrm{kV}$ applied voltage 


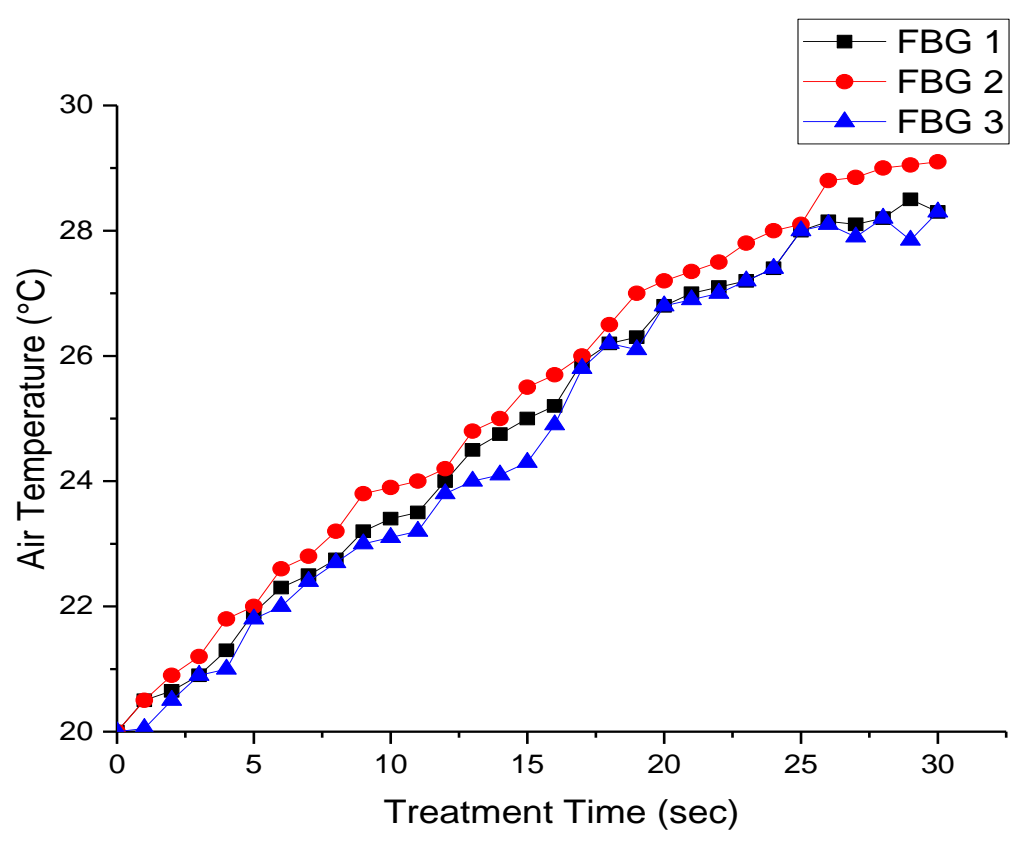

Fig. 5. Air temperature profile for $8 \mathrm{kV}$ applied voltage

Figure 6 shows the air temperature profile for $9 \mathrm{kV}$ applied voltage. The graph in Figure 6 for $9 \mathrm{kV}$ applied voltage shows that there has been a significant increase with fluctuation at certain points in air temperature measurement and monitoring, lies between 29 to $31{ }^{\circ} \mathrm{C}$ within $30 \mathrm{sec}$ treatment time. Highest air temperature profile was recorded by FBG 2, followed by FBG 1 and FBG 3.

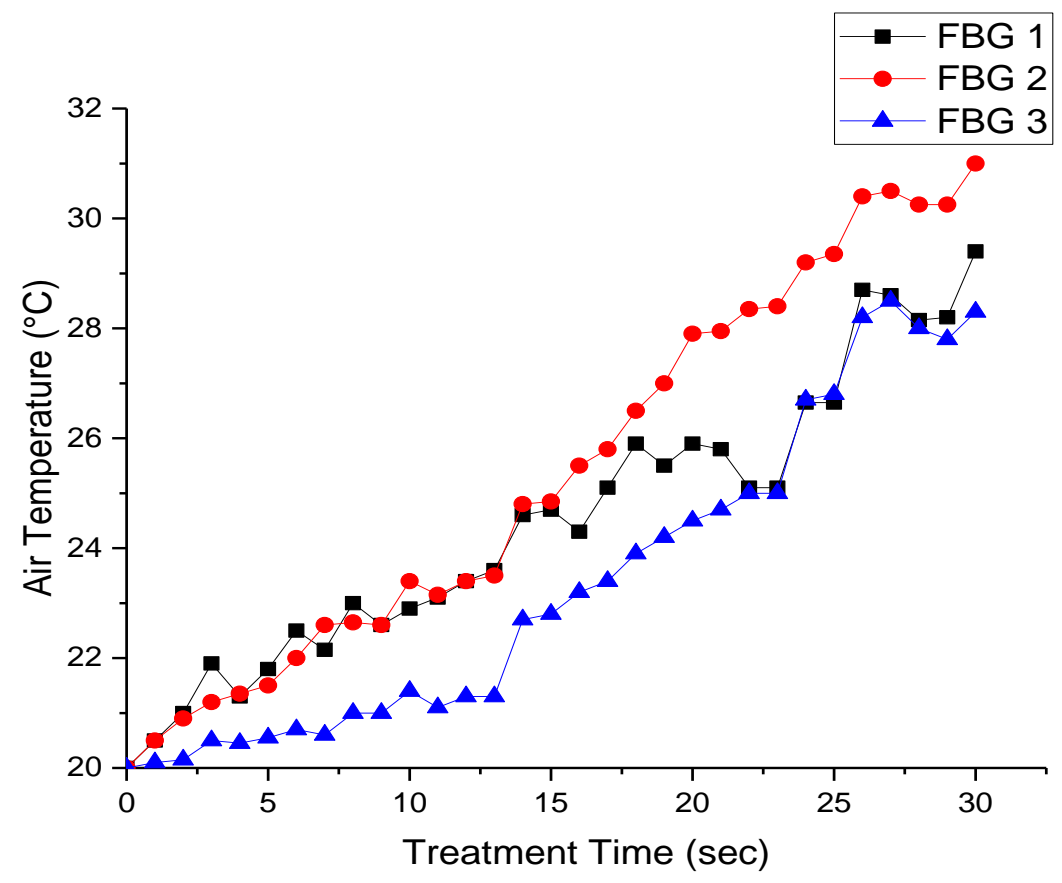

Fig. 6. Air temperature profile for $9 \mathrm{kV}$ applied voltage

Thermal behaviour shown by $9 \mathrm{kV}$ was an instantaneous air temperature rise due to further increment of applied voltage which spread the microdischarge filaments into surface discharge, eventually led to intensified discharge interactions and collisions. Intensified discharge interactions 
and collisions contributed to non-uniformity of charge distribution and electron instability which caused temperature fluctuation [29-30]. This is the cause of the air temperature instability in FBG 1, FBG 2 and FBG 3 especially for $9 \mathrm{kV}$ case. Air temperature increment was expected as it was greatly influenced by the electron emission in order to form plasma. When applied voltage increased, electron gained more energy, which caused the electron to move and vibrate vigorously. Vigorous vibration and movement of electron became excess energy (in heat form), eventually contributed to air temperature rise. The excess energy then initiated more frequent electron collision, which later on produce plasma [14]. Acceleration of electrons was induced by the electrical current produced by higher applied voltage. According to Ohm's Law and Joule's First Law, higher induced current contributed more heat due to greater dissipated power. Hence, excessive heat in plasma stream produced, eventually led to substantial air temperature rise [15].

Based on our electrode geometry design, positive current pulse is formed in plasma reactor. Positive current pulse is caused by electrons movement towards the glass tube (dielectric) from the steel wire (cathode) and ion streamer mobility from the glass tube (dielectric) to the steel wire (cathode). For this case, secondary emission effect is influenced by the steel wire, as the steel wire acts as cathode and the glass tube (dielectric) as anode. The electrons eventually experienced photo desorption from steel wire and move towards glass tube. The previous free electrons are not trapped by the steel wire surface and hence the secondary electron emission is from the steel wire surface. Higher energy is required to initiate secondary electron emission to reduce collective effect, thus led to high intensity of filamentary discharge [31].

In general, it proves that the ability of FBG is not just limited only to measure and monitor the air temperature inside plasma reactor, but it can also detect the type of discharge formation (either homogenous or filamentary discharge) based on air temperature data recorded. Unquestionably, different type of discharge might give different steel wire surface cleaning result.

\subsection{Steel Wire Surface Roughness and Surface Morphology}

Steel wire cleaning performance was further evaluated using the percentage of surface roughness reduction, with comparison of surface roughness of untreated steel wire with plasma treated steel wire using selected treatment time, which were $5 \mathrm{sec}, 10 \mathrm{sec}, 15 \mathrm{sec}, 20 \mathrm{sec}, 25 \mathrm{sec}$ and $30 \mathrm{sec}$. Limitation of treatment time up to $30 \mathrm{sec}$ is based on the evidence that plasma exposure of more than $30 \mathrm{sec}$ led to increment of root mean square (RMS) surface roughness, due to etching which led to metallographic surface modifications [32]. Since the main purpose in this research was to just clean the rusted steel wire, not up to metallographic surface modifications, we believe that treatment time up to $30 \mathrm{sec}$ is sufficient enough.

Table 2 shows the percentage of surface roughness reduction performed using $7 \mathrm{kV}, 8 \mathrm{kV}$ and 9 $\mathrm{kV}$ with treatment time of $5 \mathrm{sec}, 10 \mathrm{sec}, 15 \mathrm{sec}, 20 \mathrm{sec}, 25 \mathrm{sec}$ as well as $30 \mathrm{sec}$. The range of surface roughness reduction percentage was between $15 \%$ to $51 \%, 18 \%$ to $59 \%$ and $24 \%$ to $60 \%$ for $7 \mathrm{kV}, 8$ $\mathrm{kV}$ and $9 \mathrm{kV}$ applied voltages respectively. It is observed that higher applied voltage contributed to greater percentage of surface roughness reduction, as treatment time increased. In general, more than $25 \mathrm{sec}$ was required in order to achieve the percentage of surface roughness reduction more than $50 \%$.

Figure 7 shows the steel wire surface morphology in untreated and treated condition through optical microscope, for selected samples which recorded surface roughness reduction of more than $50 \%$. Observation through optical microscope proved that plasma treatment was clearly effective to remove and clean the rust formed in untreated steel wire. It is definitely the clear evidence of the 
ability of plasma treatment to decrease the root mean square (RMS) surface roughness and enhance the surface quality of treated samples [22-24].

Table 2

Mean absolute percentage error (MAPE)

\begin{tabular}{|c|c|c|c|c|}
\hline $\begin{array}{l}\text { Applied } \\
\text { Voltage } \\
(\mathrm{kV})\end{array}$ & $\begin{array}{l}\text { Treatment } \\
\text { Time } \\
\text { (sec) }\end{array}$ & $\begin{array}{l}\text { Surface Roughness of } \\
\text { Untreated Steel } \\
\text { Wire, } R_{a} \\
(\mu \mathrm{m})\end{array}$ & $\begin{array}{l}\text { Surface Roughness of } \\
\text { Treated Steel Wire, } \\
R_{a} \\
(\mu \mathrm{m})\end{array}$ & $\begin{array}{l}\text { Percentage of } \\
\text { Surface Roughness } \\
\text { Reduction } \\
\text { (\%) }\end{array}$ \\
\hline \multirow[t]{6}{*}{7} & 5 & 1.972 & 1.673 & 15.16 \\
\hline & 10 & 1.311 & 1.104 & 15.79 \\
\hline & 15 & 1.247 & 0.957 & 23.26 \\
\hline & 20 & 1.572 & 0.905 & 42.43 \\
\hline & 25 & 2.020 & 1.028 & 49.11 \\
\hline & 30 & 1.944 & 0.961 & 50.57 \\
\hline \multirow[t]{6}{*}{8} & 5 & 0.914 & 0.747 & 18.27 \\
\hline & 10 & 1.321 & 0.879 & 33.46 \\
\hline & 15 & 1.231 & 0.721 & 41.43 \\
\hline & 20 & 1.667 & 0.967 & 42.00 \\
\hline & 25 & 1.811 & 0.892 & 50.75 \\
\hline & 30 & 1.879 & 0.785 & 58.22 \\
\hline \multirow[t]{6}{*}{9} & 5 & 1.398 & 1.059 & 24.25 \\
\hline & 10 & 2.910 & 2.161 & 25.74 \\
\hline & 15 & 1.320 & 0.866 & 34.39 \\
\hline & 20 & 1.703 & 1.101 & 35.35 \\
\hline & 25 & 2.401 & 1.108 & 53.85 \\
\hline & 30 & 2.288 & 0.919 & 59.83 \\
\hline
\end{tabular}

Qualitative results from optical microscope indicated that higher applied voltage contributed to greater percentage of surface roughness reduction. This result reflected to the massive amount of ionization and ion bombardment performed by the higher magnitude of applied voltage. Frequent collision of electron and ion bombardment produced by higher applied voltage eventually eliminated rust formed in steel wire surface [15]. In this situation, the obtained results of steel wire surface roughness reduction as well as surface morphology from optical microscope can be related with corresponding air temperature profiles presented in previous section. Based on air temperature measurement and monitoring carried out, it has been highlighted the ability of FBG to identify the type of discharge formed based on generated air temperature profiles. Referring to previous air temperature profiles, it is clearly showed that $7 \mathrm{kV}$ and $8 \mathrm{kV}$ applied voltages formed homogenous type of plasma discharge while $9 \mathrm{kV}$ applied voltage generated filamentary type of plasma discharge. Meanwhile, based on steel wire surface roughness reduction, it is indicated that highest utilized applied voltage, $9 \mathrm{kV}$ recorded highest surface roughness reduction, followed by $8 \mathrm{kV}$ and $7 \mathrm{kV}$.

Therefore, it is concluded that the filamentary type of plasma discharge is clearly more effective in steel wire cleaning compared to homogenous type of plasma discharge. Subsequently, the main reason of filamentary type of plasma discharge effectiveness in steel wire cleaning is due to its intensified discharge interactions and collisions as well as vigorous vibration and movement of electron which bombarded to steel wire surface, thus significantly removed a large area of rusted and oxidized surface. 


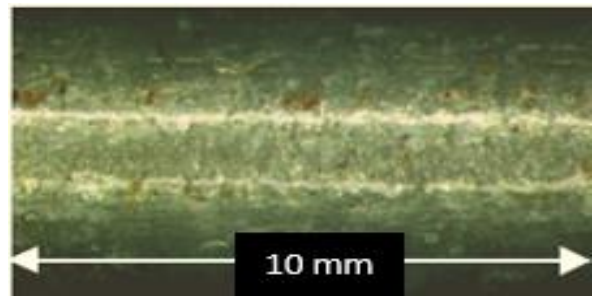

(a) Before plasma treatment

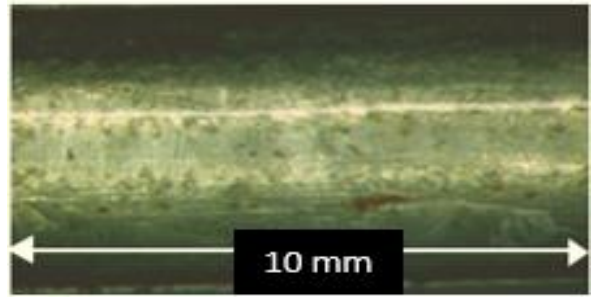

(c) Before plasma treatment

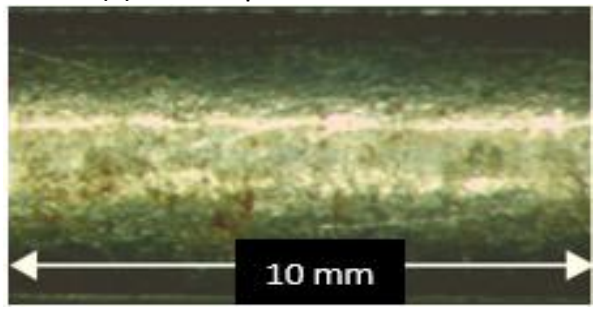

(e) Before plasma treatment

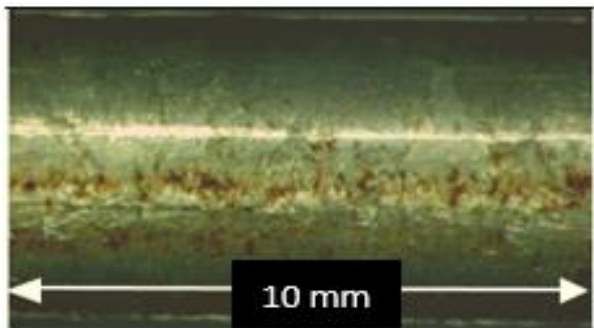

(g) Before plasma treatment

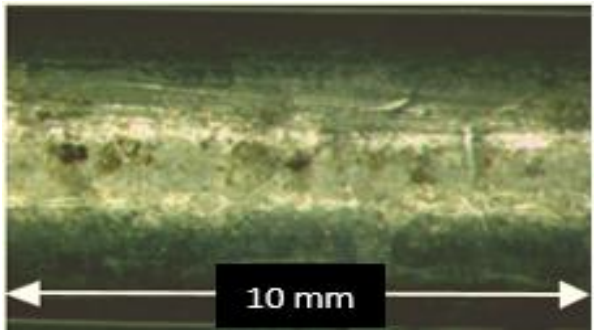

(i) Before plasma treatment

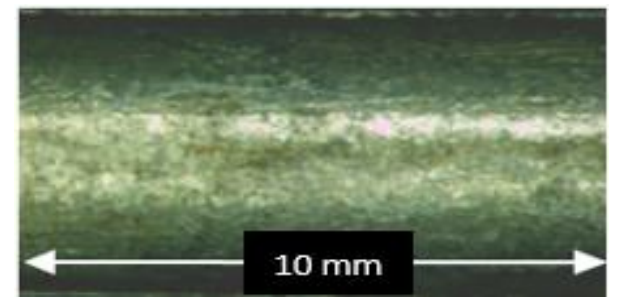

(b) After plasma treatment

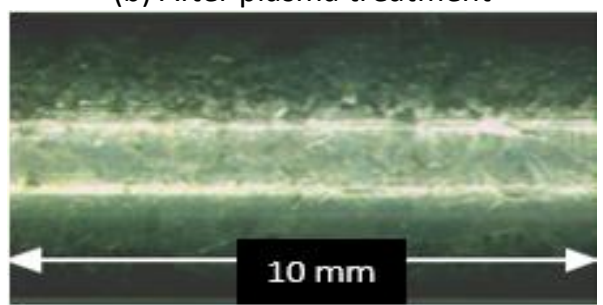

(d) After plasma treatment

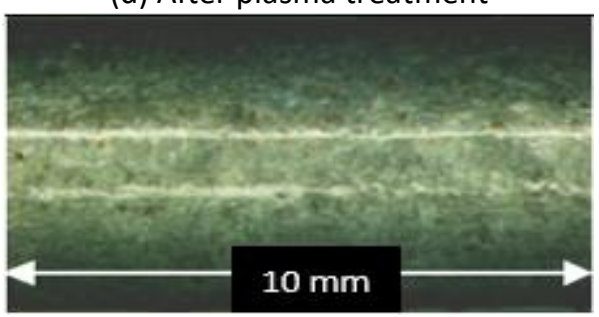

(f) After plasma treatment

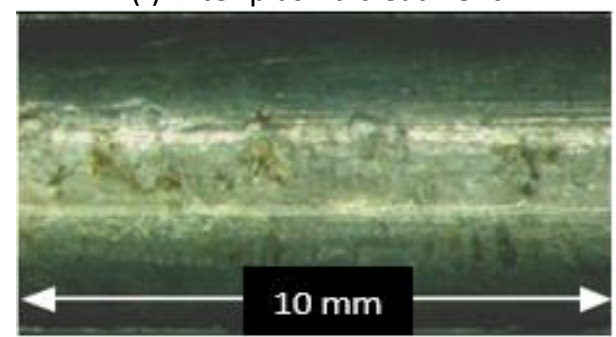

(h) After plasma treatment

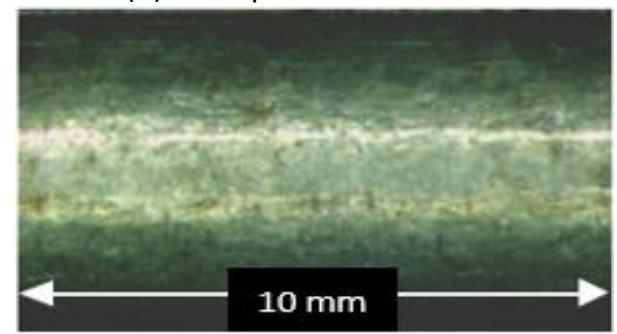

(j) After plasma treatment
$9 \mathrm{kV}, 30 \mathrm{sec}, 59.83 \%$

reduction

$8 \mathrm{kV}, 30 \mathrm{sec}, 58.22 \%$

reduction

$9 \mathrm{kV}, 25 \mathrm{sec}, 53.85 \%$

reduction

$8 \mathrm{kV}, 25 \mathrm{sec}, 50.75 \%$

reduction

$7 \mathrm{kV}, 30 \mathrm{sec}, 50.57 \%$

reduction

Fig. 7. Selected steel wire surface morphology in untreated condition (a, c, e, g, i) and treated condition (b, $d, f, h, j)$ with magnification $\times 40$

\section{Conclusions}

In this study, we have successfully revealed the ability of FBG to carry out air temperature measurement and monitoring inside the plasma reactor. Besides, the effect of type of plasma discharge (based on air temperature profile monitoring) towards the cleaning effectiveness of rusted steel wire were also successfully proved. In general, the findings of this study indicate that:

i. FBG is successfully measured as well as monitored the air temperature profiles and eventually identified the type of plasma discharge formed by $7 \mathrm{kV}, 8 \mathrm{kV}$ and $9 \mathrm{kV}$ applied voltages. Based on air temperature profiles recorded, it has been identified that $7 \mathrm{kV}$ and $8 \mathrm{kV}$ applied voltages 
formed homogenous plasma discharge while $9 \mathrm{kV}$ applied voltage generated filamentary plasma discharge.

ii. Highest surface roughness reduction is shown by $9 \mathrm{kV}$, followed by $8 \mathrm{kV}$ and $7 \mathrm{kV}$. Therefore, it is a clear result that filamentary plasma discharge formed by $9 \mathrm{kV}$ will give higher cleaning effectiveness in comparison with homogenous plasma discharge formed by both $8 \mathrm{kV}$ and 7 kV.

iii. More than $25 \mathrm{sec}$ treatment time is required for all applied voltages to achieve surface roughness reduction of more than $50 \%$.

The present findings have important implications in order to identify the type of plasma discharge formed inside the reactor, without depends on naked eye observation. The importance of discharge identification might help scientists in plasma or thermal field to match the plasma discharge intensity with suitable surface treatment or modification applications.

\section{Acknowledgement}

This research was funded by a grant from Ministry of Education of Malaysia through Fundamental Research Grant Scheme (FRGS) 7843.4F808 and Research University Grant (GUP) Tier $12524.04 \mathrm{H74.}$ First author also wants to express very profound gratitude to UTM Zamalah Scholarship for his financial assistance.

\section{References}

[1] Belkind, A., and S. Gershman. "Plasma cleaning of surfaces." Vacuum Coating and Technology November (2008): 46-57.

[2] Wandke, D., M. Schulze, S. Klingner, A. Helmke, and W. Viöl. "“3-in-1” plasma wire system." Surface and Coatings Technology 200, no. 1-4 (2005): 700-703.

https://doi.org/10.1016/j.surfcoat.2005.02.216

[3] Choi, In S., Seok W. Hwang, and Jong C. Park. "Application of medium frequency atmospheric plasma on continuous aluminum wire cleaning for magnet wire manufacturing." Surface and Coatings Technology 142 (2001): 300-305. https://doi.org/10.1016/S0257-8972(01)01069-6

[4] Korzec, D., M. Teschke, E. G. Finantu, G. Nau, and J. Engemann. "Atmospheric pressure plasma source for wire cleaning." In PROCEEDINGS OF THE ANNUAL TECHNICAL CONFERENCE-SOCIETY OF VACUUM COATERS, vol. 47, p. 455. 2004.

[5] Kettler, Roman, Paulina Cesarec, and Branko Katalinic. "Cleaning of Metal Wires by Using Rotating Thermal Plasma." Annals of DAAAM \& Proceedings (2009).

[6] Nakamura, T., C. Buttapeng, S. Furuya, and N. Harada. "Surface cleaning of metal wire by atmospheric pressure plasma." Applied surface science 256, no. 4 (2009): 1096-1100. https://doi.org/10.1016/j.apsusc.2009.05.121

[7] Hao, Wong Jun, and Lim Yuan Ming. "A comparative analysis on physical and chemical plasma cleaning effects on surfaces." In 2013 IEEE 15th Electronics Packaging Technology Conference (EPTC 2013), pp. 329-334. IEEE, 2013. https://doi.org/10.1109/EPTC.2013.6745737

[8] Ugye, J. T., A. Uzairu, S. O. Idris, and H. O. Kwanashie. "Temperature effects on the rate of reaction of plasma albumin with formaldehyde in water solution and ethanol-water-mixtures." Chemical Journal 3 (2013): 128-132.

[9] Harling, Alice M., Anna E. Wallis, and J. Christopher Whitehead. "The Effect of Temperature on the Removal of DCM using Non-Thermal, Atmospheric-Pressure Plasma-Assisted Catalysis." Plasma Processes and Polymers 4, no. 4 (2007): 463-470. https://doi.org/10.1002/ppap.200600207

[10] Kim, D-H., Y. S. Mok, and S. B. Lee. "Effect of temperature on the decomposition of trifluoromethane in a dielectric barrier discharge reactor." Thin Solid Films 519, no. 20 (2011): 6960-6963. https://doi.org/10.1016/i.tsf.2010.11.060

[11] Young Sun, Mok, and Kim Dong-Hong. "Decomposition of sulfur hexafluoride by using a nonthermal plasmaassisted catalytic process." Journal of Korean Physical Society 59 (2011): 3437. https://doi.org/10.3938/ikps.59.3437

[12] Kim, J. S., and M. A. Cappelli. "Temperature measurements in low-pressure, diamond-forming, premixed flames." Journal of applied Physics 84, no. 8 (1998): 4595-4602. 
https://doi.org/10.1063/1.368685

[13] Brohez, Sylvain, Christian Delvosalle, and Guy Marlair. "A two-thermocouples probe for radiation corrections of measured temperatures in compartment fires." Fire Safety Journal 39, no. 5 (2004): 399-411.

https://doi.org/10.1016/j.firesaf.2004.03.002

[14] Musa, Siti Musliha Aishah, RK Raja Ibrahim, and Asrul Izam Azmi. "Development of Fiber Bragg Grating (FBG) as Temperature Sensor Inside Packed-bed Non-thermal Plasma Reactor." Jurnal Teknologi 68, no. 3 (2014). https://doi.org/10.11113/it.v68.2960

[15] Nor Zazwani Rosdi, Ibrahim, RK Raja, S. M. A. Musa, Raheleh Hosseinian, Asrul Izam Azmi, and Norhayati Ahmad. "Reactor temperature profiles of non-thermal plasma reactor using fiber Bragg grating sensor." Sensors and Actuators A: Physical 244 (2016): 206-212. https://doi.org/10.1016/i.sna.2016.04.015

[16] Nihira, Takeshi, and Tadao Iwata. "Temperature dependence of lattice vibrations and analysis of the specific heat of graphite." Physical Review B 68, no. 13 (2003): 134305.

https://doi.org/10.1103/PhysRevB.68.134305

[17] Tohei, Tetsuya, Akihide Kuwabara, Fumiyasu Oba, and Isao Tanaka. "Debye temperature and stiffness of carbon and boron nitride polymorphs from first principles calculations." Physical Review B 73, no. 6 (2006): 064304.

https://doi.org/10.1103/PhysRevB.73.064304

[18] Chen, Shanshan, Arden L. Moore, Weiwei Cai, Ji Won Suk, Jinho An, Columbia Mishra, Charles Amos et al., "Raman measurements of thermal transport in suspended monolayer graphene of variable sizes in vacuum and gaseous environments." ACS nano 5, no. 1 (2010): 321-328.

https://doi.org/10.1021/nn102915x

[19] Balandin, Alexander A. "Thermal properties of graphene and nanostructured carbon materials." Nature materials 10, no. 8 (2011): 569.

https://doi.org/10.1038/nmat3064

[20] Jo, Gunho, Minhyeok Choe, Sangchul Lee, Woojin Park, Yung Ho Kahng, and Takhee Lee. "The application of graphene as electrodes in electrical and optical devices." Nanotechnology 23, no. 11 (2012): 112001. https://doi.org/10.1088/0957-4484/23/11/112001

[21] Chen, Shanshan, Qingzhi Wu, Columbia Mishra, Junyong Kang, Hengji Zhang, Kyeongjae Cho, Weiwei Cai, Alexander A. Balandin, and Rodney S. Ruoff. "Thermal conductivity of isotopically modified graphene." Nature materials 11, no. 3 (2012): 203. https://doi.org/10.1038/nmat3207

[22] Noeske, Michael, Jost Degenhardt, Silke Strudthoff, and Uwe Lommatzsch. "Plasma jet treatment of five polymers at atmospheric pressure: surface modifications and the relevance for adhesion." International journal of adhesion and adhesives 24, no. 2 (2004): 171-177. https://doi.org/10.1016/i.ijadhadh.2003.09.006

[23] Lin, Jau-Wen, and Hsi-Cherng Chang. "Surface modification of SUS304 stainless steel by atmospheric pressure Ar/N2/O2 plasma." Nuclear Instruments and Methods in Physics Research Section B: Beam Interactions with Materials and Atoms 269, no. 15 (2011): 1801-1808.

https://doi.org/10.1016/i.nimb.2011.05.004

[24] Ioanid, Emil Ghiocel, Aurelia Ioanid, Dorina Emilia Rusu, and Florica Doroftei. "Surface investigation of some medieval silver coins cleaned in high-frequency cold plasma." Journal of cultural heritage 12, no. 2 (2011): 220-226. https://doi.org/10.1016/i.culher.2010.09.004

[25] Zhou, Yan, Wenjun Zhou, Chi Chiu Chan, Wei Chang Wong, Li-Yang Shao, Jia Cheng, and Xinyong Dong. "Simultaneous measurement of curvature and temperature based on PCF-based interferometer and fiber Bragg grating." Optics Communications 284, no. 24 (2011): 5669-5672.

https://doi.org/10.1016/j.optcom.2011.08.048

[26] Tu, Xin, Helen J. Gallon, and J. Christopher Whitehead. "Transition behavior of packed-bed dielectric barrier discharge in argon." IEEE Transactions on Plasma Science 39, no. 11 (2011): 2172-2173. https://doi.org/10.1109/TPS.2011.2160289

[27] Brandenburg, R., Z. Navrátil, J. Jánský, P. St'Ahel, D. Trunec, and H. E. Wagner. "The transition between different modes of barrier discharges at atmospheric pressure." Journal of Physics D: Applied Physics 42, no. 8 (2009): 085208. https://doi.org/10.1088/0022-3727/42/8/085208

[28] Massines, Françoise, N. Gherardi, N. Naudé, and P. Ségur. "Recent advances in the understanding of homogeneous dielectric barrier discharges." The European Physical Journal-Applied Physics 47, no. 2 (2009). https://doi.org/10.1051/epjap/2009064 
[29] Huang, Zhiming, Lin Yang, Yanpeng Hao, and Licheng Li. "Dynamic Characteristics of Dielectric Barrier Columnar Discharge During Its Decay." IEEE Transactions on Plasma Science 44, no. 11 (2016): 2568-2575.

https://doi.org/10.1109/TPS.2016.2594195

[30] Russ, Holger, Manfred Neiger, and Jurgen E. Lang. "Simulation of micro discharges for the optimization of energy requirements for removal of NO/sub x/from exhaust gases." IEEE transactions on plasma science 27, no. 1 (1999): 38-39.

https://doi.org/10.1109/27.763019

[31] Tay, W. H., S. L. Yap, and C. S. Wong. "Electrical characteristics and modeling of a filamentary dielectric barrier discharge in atmospheric air." Sains Malaysiana 43, no. 4 (2014): 583-594.

[32] Hicks, R. F., S. E. Babayan, J. Penelon, Q. Truong, D. S. F. Cheng, V. V. Le, J. Ghilarducci, A. G. Hsieh, Joseph M. Deitzel, and John W. Gillespie Jr. "Atmospheric plasma treatment of polyetheretherketone composites for improved adhesion." In SAMPE Fall Technical Conference Proceedings: Global Advances in Materials and Process Engineering, pp. 1-9. 2006. 